\title{
Bioinspired cellular sheath-core electrospun non-woven mesh
}

\author{
Hussain R. Rizvi ${ }^{1} \cdot$ Nandika D'Souza $^{1,2}$ (D) $\cdot$ Brian Ayre $^{3} \cdot$ Dinesh Ramesh $^{2}$
}

Received: 23 May 2019 / Accepted: 10 July 2019 / Published online: 13 August 2019

(C) The Author(s) 2019

\begin{abstract}
Fibers are valuable to biomedical applications. Used as sutures or meshes, there is an increased dual need to provide functionality such as drug delivery. Porosity represents a high surface area to volume architecture. Coaxial fibers with porous and non-porous layers offer a new design framework for fiber design that can resolve dual needs of mechanical robustness with transport phenomena. Using preferential solubility of a polymer in supercritical $\mathrm{CO}_{2}$, we develop a new architecture using biocompatible polymers based on porous core-sheath fiber fabrication technique. Polycaprolactone was selected as the $\mathrm{CO}_{2}$ miscible phase and Poly(butyrate adipate terephthalate)(PBAT) as the immiscible phase. The mechanical performance of the fibers was investigated using quasi static and dynamic loading. SEM images indicate no physical detachment of the two polymer surface after $\mathrm{CO}_{2}$ exposure indicating a successful amalgamation of polymers at the boundary of core and sheath. PCL as a sheath and as a core showed an increase of $650 \%$ and $468 \%$ in tensile strength compared to pristine PCL and PBAT. Introduction of porosity on the surface of coaxial fiber fPCL(cPBAT) further enhanced the yield strength increases by $40 \%$. Dynamic mechanical analysis was used to analyze the viscoelastic properties of the fibers. The storage and loss modulus for coaxial fibers shows superior modulus throughout the glassy, glass transition and rubbery region as compared to the pristine PCL and PBAT, showing enhancement in both the elastic and viscous response of the material. The results indicate a new approach that is free of volatile organic solvents to manipulate the architecture of the cross-section of the electrospun fiber and tailor mechanical properties to the required application.
\end{abstract}

\section{Introduction}

Fibers are invaluable in biomedical applications whether as sutures or part of tissue scaffolds or drug delivery patches as woven and non-woven fabric. The capability to mimic an extracellular matrix (ECM) with specified functionality has opened new endeavors in the field of tissue engineering and drug delivery making porous architectures attractive. Increasing the surface area for drug delivery is enabled through porosity but completely porous polymers are not durable. Both mechanical and transport properties are critical to

Nandika D'Souza

ndsouza@unt.edu

1 Department of Mechanical and Energy Engineering, University of North Texas, Union Circle \#311098, Denton, TX 76203-5017, USA

2 Department of Material Science and Engineering, University of North Texas, 1155 Union Circle \#305310, Denton, TX 76203-5017, USA

3 Department of Biological Sciences, 1155 Union Circle \#305310, Denton, TX 76203-5017, USA their function. Mechanical properties of durability and flexibility and transport properties of both fluid flow and drug release are influenced by fiber density where both constituent material properties and architecture are critical parameters. The cross-sectional architecture of fibers has been an underexplored variable. Nature inspired design has had a positive impact on design of new nacre inspired structures and coatings as well as gecko inspired adhesives. Synthetic fiber cross-sections are either solid circular cross section (glass/carbon) or grown around a core fiber (boron). These fibers have significant contributions to stiffness but limited contributions to toughness. In contrast, plant fibers consist of porous crosssectional architecture (Fig. 1) whose physical morphology and mechanical properties depend on the age, and condition of growth and development. In our previous work on kenaf bast fiber, we have compared two different post processing retting environments in plant fibers to create porous and non-porous fibers with core-shell architectures [2, 3]. Using an alkali retting approach, fibers were formed where the plant cell walls collapsed with few active functional groups that were available on the surface. In contrast, we used a pectinase environment to create fibers with a porous cross section and active carboxy groups remained on the fiber surface. Both storage 
Fig. 1 Porous cross section of plant fibers

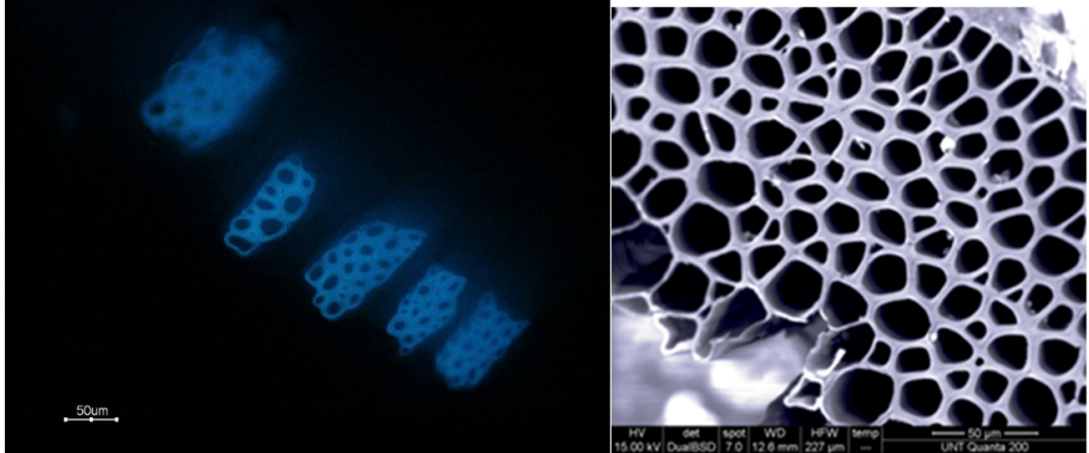

and loss moduli were found to be superior when the porosity was preserved indicating fiber stiffness and fiber damping contribute to mechanical performance [1-23]. Based on the inference that porosity and mechanical properties of the cell wall can contribute to the mechanical performance, in this paper, we examine the impact of synthetic bioninspired fiber design on mechanical performance of fibers. Two architectures are examined: porosity on the surface and porosity in the core. We are motivated by the extensive value biocompatible fibers have in biomedical applications in drug delivery and as textiles as scaffolds. The use of chemical foaming agents and its residue has remained a challenge as release over time of the chemicals presents a toxicity challenge.

Hollow fibers and foamed fibers have been previously explored, but coaxial fibers and particularly foamed coaxial fibers have not been researched to our knowledge. The mechanical properties of fibers composites can be highly influenced by various parameters including pore size, fibers diameter, type of polymer and solvent, physical and chemical interaction between the blends and/or reinforcing particle and defects. Due to multiple parameters there is inconsistency in the reported mechanical properties of porous electrospun fibers and the underlying principle are usually difficult to extract. Porosity is typically through preferential solubility of an organic solvent in one phase but correlation to the properties of the pure polymer is challenging. For example, Guan et al. [4] investigated a blend of polyoxymethylene and PLLA. Dissolution of the PLLA using chloroform resulted in porous fibers. The results showed modulus of the porous polyoxymethylene (POM) fabric slightly greater than the POM/PLLA blend and the strain at break reduced from $540 \%$ for blend to $280 \%$ for the foamed fibers. Xu et al. [5] report that mechanical properties of porous magnesium-carbon nanofiber composites have an inverse relation to the percentage of porosity. Yield strength of the composite decreased from 63 to $13 \mathrm{MPa}$ as the porosity increased from 24 to $50 \%$. Yin et al. [6] show a similar trend with PLGA fibers, a reduction of modulus from 14.7 to $0.37 \mathrm{MPa}$ as the porosity percentage increase from 35 to 70 . Additionally, they showed that the modulus not only depends on the percentage of pores but also on the morphology of pores. Cooper et al. [7] reported reduction of bead structure (defects) and pore size of the electrospun fibers causes an increase in the modulus and tensile strength of polybutylene succinate fibers. Tensile strength of porous PLLA and poly (LLA-co-CL) fibers decreases from 0.77 to $0.36 \mathrm{MPa}$ as the pore diameter increases from 298 to $408 \mathrm{~nm}$. Huan et al. [8] showed reinforcement of PLA with cellulose nanocrystal induce porosity but also improved the tensile strength and modulus of fibers at low loading level; however, increase in cellulose content higher than $10 \%$ had deteriorating effect on the mechanical properties due by high porosity. The question then arises is whether the equi-strain condition in coaxial fibers can cause greater than additive benefits to the fiber mechanical properties not obtained thus far in foamed fibers.

Electrospinning is a cost-effective and efficient method to create polymer-based nano/microscale fibers, having high surface area. It works on the principle of electrostatic charge difference to generate polymer fibers ranging from micron to nano-scale [9]. Sun et al. [10] first introduced a modification in the technique creating nanofibers using two different materials in a core-sheath morphology, where the core usually provides the physical properties and sheath gives functionality to the fiber [11]. The hollow structure in electrospun fibers is normally achieved using organic solvents by phase separation method where polymer solution becomes thermodynamically unstable and separates into polymer-rich phase and solventrich phase, after evaporation of solvent, a porous structure is obtained [12]. This methodology can be categorized based on the parameter causing separation: vapor-induced phase separation (VIPS) [13], thermally induced phase separation (TIPS) [14], and non-solvent-induced phase separation (NIPS) [15-17]. Further techniques to introduce porosity include post treatment of the fiber in a non-solvent bath, selective removal of one component of blend [18], salt leaching and/or calcination at high temperature [19].

The use of $\mathrm{CO}_{2}$ has a physical foaming agent has advantages in mitigating the adverse effects of organic solvents and cross-linking agents. The use of environmentally friendly, low cost gas foaming for polymer processing was first proposed

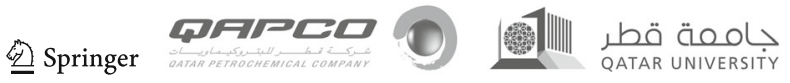


by Mooney et al. [20]. Due to high solubility and diffusivity of carbon dioxide $\left(\mathrm{CO}_{2}\right)$ at low supercritical values $(\mathrm{Pc}=$ 7.4 $\mathrm{MPa}$ and $\mathrm{Tc}=31{ }^{\circ} \mathrm{C}$ ) miscibility with some polymers induces swelling and plasticization (decrease in $\mathrm{T}_{\mathrm{g}}$ ) [21]. Upon depressurization, cells starts to nucleate as $\mathrm{CO}_{2}$ leaves the polymer and pores are formed. The extent of foaming in various polymer is well documented and is dependent upon its affinity with carbon dioxide in liquid and critical state [22, 23, $24,25]$. The use of sub or supercritical $\mathrm{CO}_{2}$ to generate porosity in electrospun fibers is currently limited. Only few studies report the manufacturing of electrospun fibers in $\mathrm{CO}_{2}$ atmosphere. In which $\mathrm{CO}_{2}$ extract the solvent from the surface of polymer solution creating a vitrified polymer skin [26] and hollow fibers $[27,28]$ resulting in poor mechanical properties. Moreover, the fiber has normally larger diameter as they are unable to stretch and elongate before depositing on the collector. To avoid these shortcoming, we propose a two-step manufacturing process in which first coaxial fibers are created, then porosity is introduce using benign gas foaming. Using this method, it is possible to design the cross section of electrospun fibers by creating highly porous structure either in the core or surface of the coaxial fibers.

Applications of porous fibers are widespread with an increasing value for sensing [29], environmental decontamination [30], energy storage [31] biomedical drug delivery [32, $33]$, and tissue scaffolds [34, 35, 36]. However, the effective utilization of the nanostructured fabric is contingent to mechanical performance including high strength, stiffness, toughness and stable response under cyclic loading. The synergy of these properties is highly desirable in the field of polymer-based composites. In this paper, we analyze the underexplored variable of cross-sectional architecture of fibers in design of fiber-reinforced composite. Herein, we report a method to tailor the mechanical properties of composite fibers by varying the composition and architecture of electrospun fibers. The effect of different cross-sectional morphology on the mechanical performance of the coaxial fibers is investigated under tensile quasi-static and dynamic loading. Pure polymers, coaxial fibers, and foamed fibers in core-sheath architectures are investigated as shown in Fig. 2.

\section{Experimental}

\subsection{Materials}

Poly(butyrate adipate terephthalate)(PBAT) Ecoflex® ${ }^{\circledR}$ F BX 7011 (MW $40 \mathrm{kDa}, \mathrm{BASF}$ Germany) and Poly ( $\varepsilon$ caprolactone) (PCL) (MW $50 \mathrm{kDa}$, Union Carbide Corporation) were used as received. Chloroform containing amylenes as a stabilizer, ACS reagent with $99.8 \%$ purity and acetone purchased from Sigma-Aldrich were used as a solvent for the electrospinning process. All chemicals were used without further purification.

\subsection{Preparation of electrospun fibers}

Two separate solutions were prepared by dissolving $10 \%$ by wt. of PBAT and $30 \%$ by wt. of PCL separately in chloroform at $40{ }^{\circ} \mathrm{C}$ for $1 \mathrm{~h}$. To get coaxial fiber meshes, a customized T-shaped needle having an outer diameter of 0.038 in and an inner diameter of 0.019 in from VITA Needle Company was used. The flow rate was maintained at $0.03 \mathrm{ml} / \mathrm{min}$ with the help of a syringe pump by New Era Pump Systems, Inc. to have a continuous flow of polymer solution. The electrical voltage was increased gradually to a critical value of $9 \mathrm{kV}$ to have a uniform stream of solution from the tip of the needle using a DC Voltage supply (Gamma High Voltage Research). Further increase in voltage causes the separation of the stream into two, resulting in separate fibers for PCL and PBAT. Voltage lower than $9 \mathrm{kV}$ results in dripping of the solution. Fibers were collected at a mandrel collector at a distance of $15 \mathrm{~cm}$ from the tip of the needle. The collector was grounded to create the voltage difference between the needle and the collector. Figure 3 shows the schematic of fabrication setup. The diameters of the core and sheath were a consequence of the flow rate needed to keep the flow continuous avoiding the beading up that occurs from low entanglements or the absence of fiber form that occurs from a too high flow rate. The die was kept constant for all fibers manufactured.

Fig. 2 Pictorial description of a $\mathrm{fPCL}(\mathrm{cPBAT})$ and $\mathbf{b}$ PBAT(cfPCL) coaxial fiber

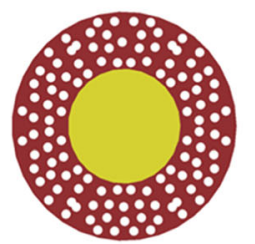

a

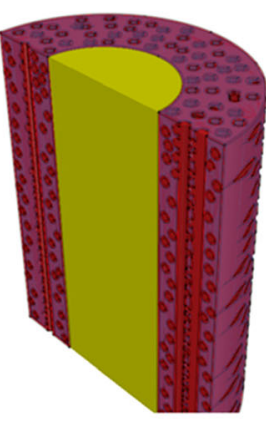

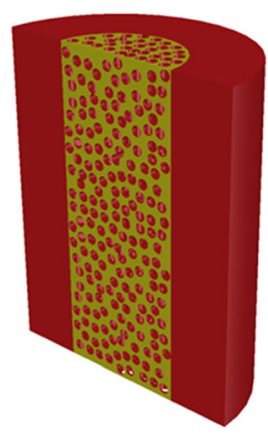

b

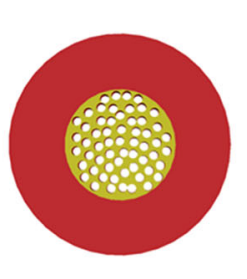

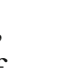




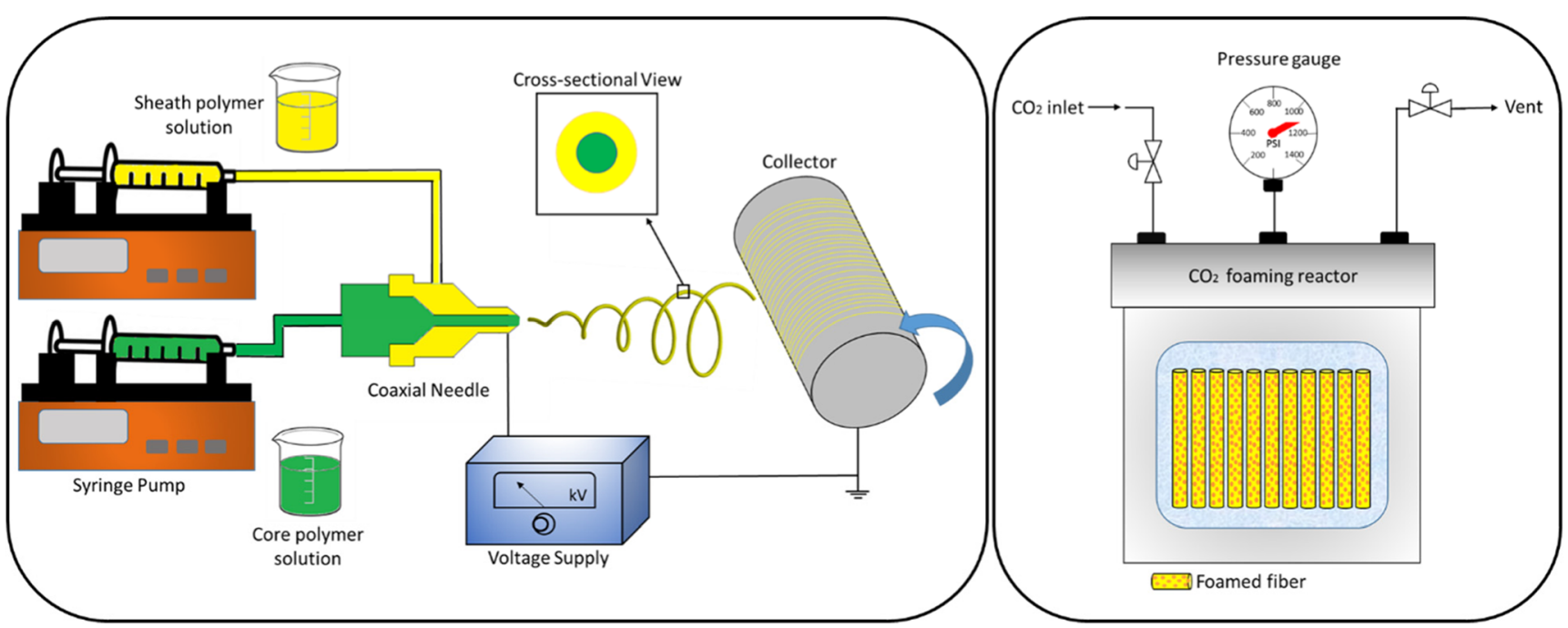

Fig. 3 Schematic of coaxial electrospinning and $\mathrm{CO}_{2}$ foaming rector used for fabrication of porous fibers

\section{$2.3 \mathrm{CO}_{2}$ foaming of the fibers}

The as-spun fiber mesh was exposed to supercritical $\mathrm{CO}_{2}$ in a customized foaming setup with a controlled temperature chamber. The pressure maintained in the chamber was $1100 \mathrm{psi}$ at a temperature of $32{ }^{\circ} \mathrm{C}$. The soaking time for the carbon dioxide to infuse into a $\mathrm{CO}_{2}$ miscible polymer (PCL) placed in the core and the sheath of the fibers was $30 \mathrm{~min}$. Following this, the chamber was depressurized rapidly within $10 \mathrm{~s}$ causing the release of $\mathrm{CO}_{2}$ from the fibers resulting in a porous structure. Higher foaming time causes an increase in the pore diameter which results in fiber breakage. In this paper, we use PCL as the porous constituent and PBAT as the $\mathrm{CO}_{2}$ immiscible system. The core constituent is bracketed together with the alphabet "c." Thus PCL (cPBAT) would be PCL sheath in a PBAT core. The foamed component has the alphabet "f." Thus PBAT(cfPCL) would denote a foamed PBAT(cPCL) fiber where the sheath is PBAT and the PCL is the core. PCL is the only polymer that is foamed as PBAT and is immiscible and demonstrated no swelling or dimensional changes when processed in $\mathrm{CO}_{2}$ at the same conditions.

\subsection{Morphological characterization}

Surface morphology of fiber mesh and foamed coaxial fibers was observed in a scanning electron microscope (FEI Nova NanoSEM 230). All of the samples were sputter coated with carbon particles to make them resistive to irradiation by reducing the charge developed on the surface. The coated samples were analyzed at an accelerating voltage of $15 \mathrm{kV}$ at a spot size of 6 . A working distance of $5 \mathrm{~mm}$ was used to capture the images.
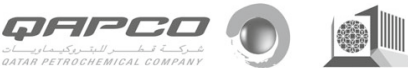
جـ

\subsection{Tensile testing}

The tensile properties of fiber mesh and foamed samples were determined using RSA III (TA Instrument, New Castle, DE) in a transient mode using standard extension mode test as reported by $\mathrm{Pu}$ et al. [37]. The uniaxial fixture was used for the samples cut in a rectangular shape with the dimensions of $15 \mathrm{~mm} \times 10 \mathrm{~mm}$, having a thickness in the range of $0.075 \pm$ $0.025 \mathrm{~mm}$ were used. All the samples were tested at a strain rate of $5 \mathrm{~mm} / \mathrm{min}$.

\subsection{Dynamic mechanical analysis (DMA)}

To measure the viscoelastic properties of the electrospun fibers and foamed sample, DMA was performed using RSA III. Rectangular-shaped samples having dimensions of $15 \mathrm{~mm} \times$ $10 \mathrm{~mm}$ with a thickness of $0.075 \pm 0.025 \mathrm{~mm}$ were used. Initially, the strain amplitude sweep test was performed at $1 \mathrm{~Hz}$ to determine the linear viscoelastic region. Next, the samples were scanned using dynamic temperature ramp test from -80 to $40{ }^{\circ} \mathrm{C}$ at the heating rate of $5^{\circ} \mathrm{C} / \mathrm{min}$. Parameters used were a frequency of $1 \mathrm{~Hz}$ and strain amplitude calculated from strain sweep test was set to $0.12 \%$.

\subsection{Differential scanning calorimeter (DSC)}

Thermal properties of the electrospun fibers and $\mathrm{CO}_{2}$ foamed samples were studied using Perkin Elmer DSC6 differential scanning calorimeter, equipped with a chiller. Heating scans were performed from 20 to $200{ }^{\circ} \mathrm{C}$ at a rate of $10{ }^{\circ} \mathrm{C}$ per minute to calculate the melting temperature and heat of enthalpy. The samples were held at $200^{\circ} \mathrm{C}$ for $1 \mathrm{~min}$ to stabilize. Next, they were cooled from 200 to $20^{\circ} \mathrm{C}$ at a rate of $10^{\circ} \mathrm{C}$ to calculate the recrystallization temperature and enthalpy of crystallization. The degree of crystallization of each sample 
was calculated using enthalpy of heating and the theoretical value of $100 \%$ crystalline enthalpy of heating for PCL and PBAT polymer. This result is important as the crystallinity of the fibers hinders degradation and enhances stiffness and tensile strength [38].

\section{Results and discussion}

\subsection{Physical morphology}

SEM images were used to characterize the surface morphology and cross-sectional structure of the $\mathrm{CO}_{2}$ foamed coaxial fibers. Figure $4 \mathrm{a}, \mathrm{b}$ shows the surface and cross section of the fPCL(cPBAT) coaxial fiber respectively, as the $\mathrm{CO}_{2}$ miscible polymer PCL was at the skin of coaxial fiber. We observe a porosity at the surface while a solid $\mathrm{CO}_{2}$ immiscible polymer PBAT surrounded by the porous sheath can be observed in Fig. 4 b. Figure $4 \mathrm{c}$ and d shows the surface and cross section of PBAT(cfPCL) fibers. As the $\mathrm{CO}_{2}$ immiscible polymer (PBAT) was at the sheath of the fibers, there was no porosity evident at the surface, whereas the core shows uniform porosity throughout the cross section (Fig. $4 \mathrm{~d}$ ). Moreover, no physical detachment of the two polymer surfaces was observed after $\mathrm{CO}_{2}$ exposure indicating a successful amalgamation of polymers at the boundary of core and sheath. Table 1 lists the diameter of the fibers obtained.

Porosity present in the core and surface of the fibers were further examined using image processing software ImageJ for pore size $(D)$, cell density $\left(N_{0}\right)$, and linear cell density, using

Fig. 4 SEM images of a PCL, $\mathbf{b}$ fPCL, $\mathbf{c}$ fPCL(cPBAT), $\mathbf{d}$ crosssectional view of fPCL(cPBAT), e PBAT(cfPCL), and $\mathbf{f}$ crosssectional view of PBAT(cfPCL) electrospun fibers

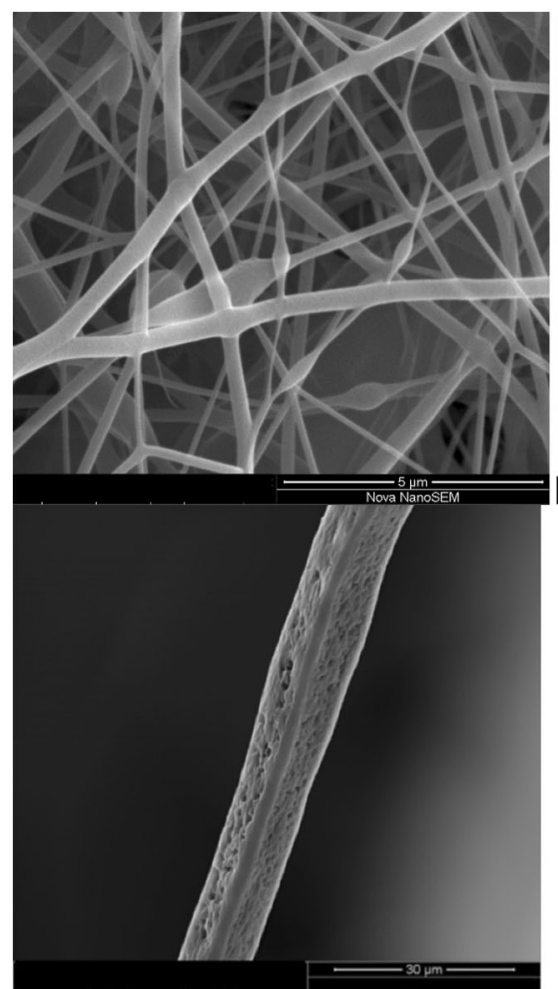

a

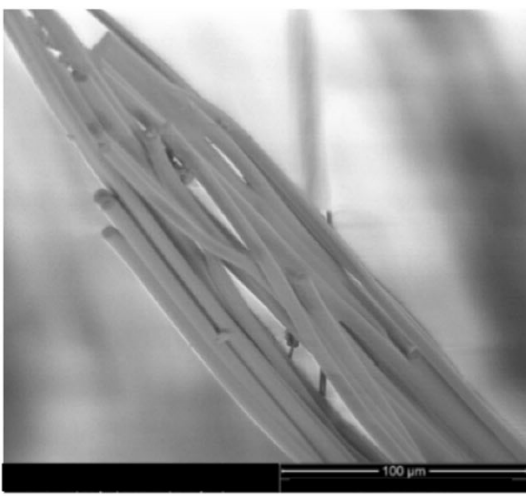

C

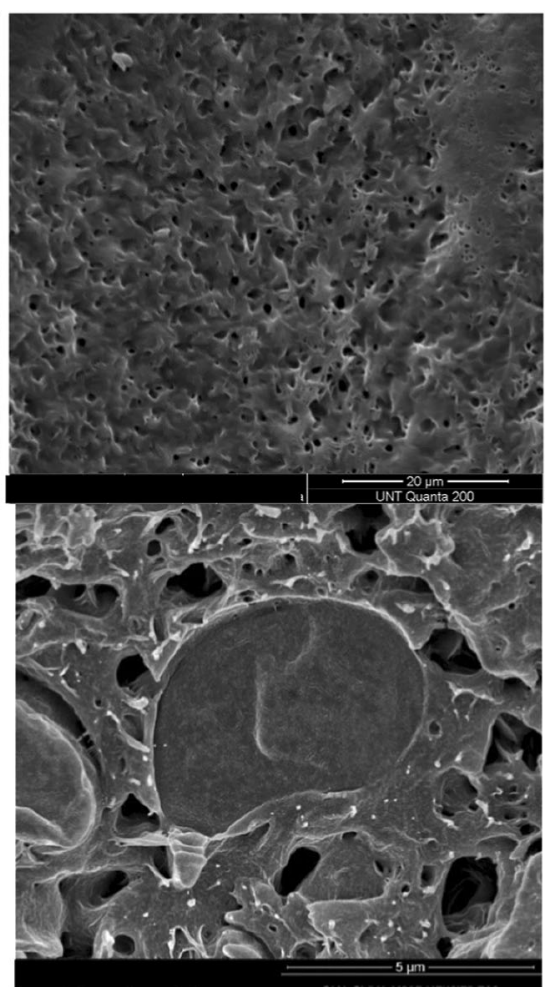

b

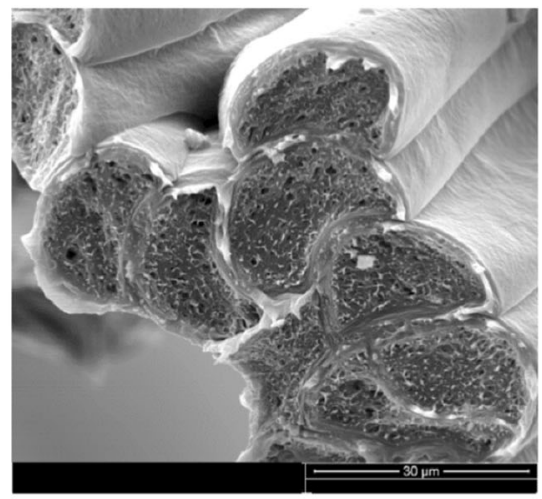

d 
Table 1 Diameter of electrospun fibers

\begin{tabular}{llll}
\hline & Total diameter $(\mu \mathrm{m})$ & Core diameter $(\mu \mathrm{m})$ & Sheath thickness $(\mu \mathrm{m})$ \\
\hline PBAT & $5.56 \pm 0.51$ & - & - \\
PCL & $0.34 \pm 0.12$ & - & - \\
PBAT(cPCL) & $20.95 \pm 2.39$ & $16.95 \pm 2.21$ & $2.11 \pm 0.34$ \\
PCL (cPBAT) & $6.26 \pm 1.01$ & $3.92 \pm 0.67$ & $1.17 \pm 0.34$ \\
PBAT(cfPCL) & $22.14 \pm 3.39$ & $18.16 \pm 3.2$ & $2.12 \pm 0.31$ \\
fPCL(cPBAT) & $7.06 \pm 1.75$ & $3.92 \pm 0.67$ & $1.57 \pm 0.54$ \\
\hline
\end{tabular}

the method described by Kumar et al. [39]. The results are listed in Table 2. Cell dimensions of the PCL are the same, independent of whether the PCL was foamed in the core or in the sheath. However, we observe almost threefold increase in the pore (cell) density for the foamed PCL(cPBAT) sample. This increase in the pore (cell) density may be due to the higher exposed area resulting in an ease in $\mathrm{CO}_{2}$ release and consequential porosity on the surface during depressurization.

\subsection{Thermal properties}

The differential scanning calorimeter technique was used to investigate the thermal behavior of the fibers shown in Fig. 5. The DSC results of pristine PCL and PBAT show the melting point at $59{ }^{\circ} \mathrm{C}$ and $122{ }^{\circ} \mathrm{C}$ respectively. The results of coaxial PCL(cPBAT) and PBAT(cPCL) show two peaks during the heating cycle of each sample. First, a sharp endothermic peak around $\sim 60{ }^{\circ} \mathrm{C}$ was observed showing the melting temperature of PCL has a more crystalline structure, while a second broad peak around $\sim 125^{\circ} \mathrm{C}$ was observed indicating the melting point of PBAT polymer which has a predominantly amorphous structure. The enthalpy of melting $\left(\Delta \mathrm{H}_{\mathrm{m}}\right)$ was calculated based on the areas under the solid-liquid phase change peaks of electrospun fibers using the thermal analysis software affiliated with the equipment. From Table 3, it can be observed that the heat of fusion of PBAT reduces significantly for coaxial fibers.

Figure 6 shows recrystallization temperature of PCL and PBAT at about $38^{\circ} \mathrm{C}$ and $95^{\circ} \mathrm{C}$, observed during the cooling cycle. Interestingly for all coaxial fibers, the recrystallization temperature shifted to lower temperatures. The magnitude of enthalpy of crystallization $(\Delta \mathrm{Hc})$ also reduces significantly. These changes might be due to the physical interaction of polymer chains. The effect of $\mathrm{CO}_{2}$ foaming on the degree of crystallization of PCL and PBAT were calculated for the fibers using following relations.

$\chi_{\mathrm{PCL}}(\%)=\frac{\Delta H_{m, \mathrm{PCL}}}{\Delta \mathrm{H}_{m, \mathrm{PCL}}^{0}(1-x)} \times 100 \%$
$\chi_{\mathrm{PBAT}}(\%)=\frac{\Delta H_{m, \mathrm{PBAT}}}{\Delta \mathrm{H}_{m, \mathrm{PBAT}}^{0}(x)} \times 100 \%$

where $\Delta H_{m, \text { PCL }} \Delta H_{m, \text { PBAT }} \Delta H_{m, \mathrm{PCL}}^{0} \Delta H_{m, \mathrm{PBAT}}^{0}$ are the enthalpy of melting of $100 \%$ crystalline PCL taken as $139 \mathrm{~J} / \mathrm{g}$ [25] and $100 \%$ crystalline PBAT taken as $114 \mathrm{~J} / \mathrm{g}$ [26] respectively, and $x$ PCL(cPBAT) coaxial fibers to supercritical $\mathrm{CO}_{2}$, the degree of crystallization of PCL decreases from 67.6 to $60.1 \%$, whereas for PBAT, it remains almost same around $1.8 \%$. Similarly, for PBAT(cPCL) system the degree of crystallization of PCL remains similar before and after foaming around $42 \%$, whereas for PBAT, it decreases from $10.7 \%$ to $7.1 \%$.

$\chi_{\text {total }}=(1-x)\left(\chi_{\mathrm{PCL}}\right)+(x)\left(\chi_{\mathrm{PBAT}}\right)$

The overall degree of crystallization was calculated using Eq. 3 which shows a decrease from $52.1 \%$ for PCL(cPBAT) coaxial fibers to $46.5 \%$ for the foamed samples. Similarly, for PBAT(cPCL) system, there is a decrease from 36.1 to $33.4 \%$. By examining the values heat of fusion $\left(\Delta \mathrm{H}_{\mathrm{m}}\right)$ and heat of crystallization $\left(\Delta \mathrm{H}_{\mathrm{c}}\right)$ in Table 3 , it can be observed that the heat generated for the polymer reduce significantly if they are present in the core of the coaxial fiber.

\subsection{Mechanical properties of electrospun fabric}

In typical polymer fiber composites, the interface between the fiber and matrix is critical to stress transfer efficiency. High interfacial strength plays vital role in effective reinforcement and limits fiber pull out and delamination. Herein, we spun two polymers using a coaxial electrospinning technique to achieve strong interface between PCL and PBAT present in the core and sheath of fiber architecture, creating fiber composite. Mechanical performance was measured using quasistatic tensile test and dynamic mechanical analysis and also compared with the constituent of unfoamed fibers and pristine PCL and PBAT. 
Table 2 Pore (cell) density and average cell diameter of the foamed fibers

\begin{tabular}{llll}
\hline & $\begin{array}{l}\text { Cell density }\left(N_{0}\right) \\
(\text { cells/cm }\end{array}$ & $\begin{array}{l}\text { Linear cell density } \\
\left(\text { cells } / \mathrm{cm}^{2}\right)\end{array}$ & $\begin{array}{l}\text { Cell diameter }(D) \\
(\mu \mathrm{m})\end{array}$ \\
\hline Foamed PCL(cPBAT) & $8.57 \times 10^{11}$ & $9483 \pm 595$ & $0.377 \pm 0.24$ \\
Foamed PBAT(cPCL) & $2.68 \times 10^{11}$ & $6414 \pm 519$ & $0.374 \pm 0.20$ \\
\hline
\end{tabular}

\subsubsection{Quasi-static tensile test}

The stress-strain curves of PCL, PBAT, and the two in coresheath morphology are shown in Fig. 7. PCL has high stiffness depicted by Young's modulus of $30.7 \mathrm{MPa}$ and low elongation at break compared to soft features of PBAT with modulus of $1.85 \mathrm{MPa}$ and high elongation before fracture. The mechanical performance of the coaxial fibers can be expected to be based on the contribution of the core and sheath polymer. However, the tensile test shows coaxial manufacturing with these two polymer results in enhancement in tensile strength, modulus, and yield stress in both core-sheath architecture fabrics as compared to the pristine polymer fibers. Porosity in the core and/or sheath plays a critical role on the mechanical properties of coaxial fabric. Figure $7 \mathrm{~b}$ shows the stress-

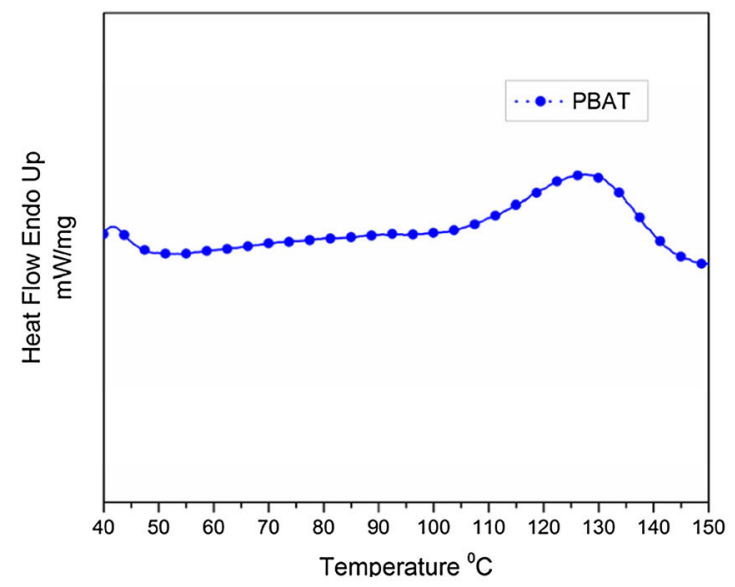

a

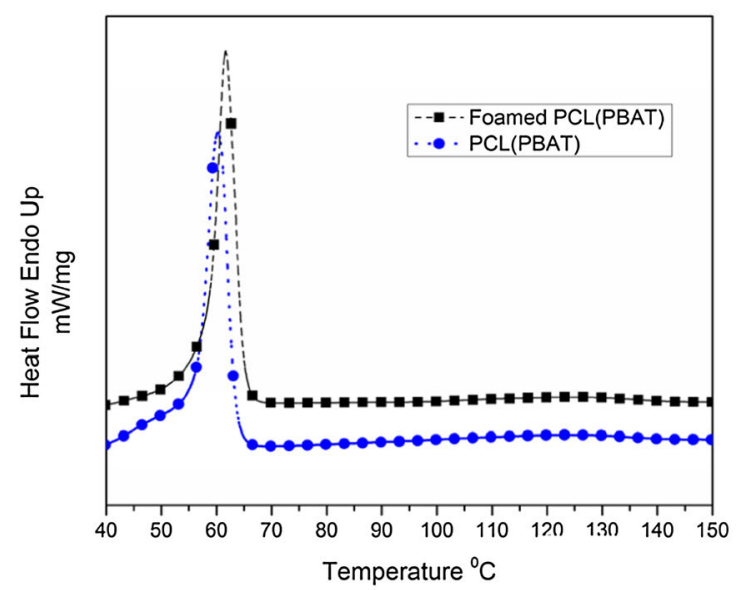

C strain curve of foamed fabric of pristine PCL (cfPCL), and foamed coaxial mats PBAT (cfPCL), fPCL (cPBAT). Tensile strength and modulus of coaxial fibers having pore in the core [PBAT(cfPCL)] were measured to be $1.62 \pm 0.57 \mathrm{MPa}$ and $33.2 \pm 4.38 \mathrm{MPa}$ and for pores in the sheath [PBAT(cfPCL)] showed high tensile strength and modulus as of compare 2.23 $\pm 0.24 \mathrm{MPa}$ and $70.9 \pm 10.3 \mathrm{MPa}$ respectively. These values are still higher than both the individual component PPCL ( $E=$ 25.7 MPa, $\left.\sigma_{\mathrm{y}}=0.36 \mathrm{MPa}\right)$ and PBAT $\left(E=1.85 \mathrm{MPa}, \sigma_{\mathrm{y}}=\right.$ $0.41 \mathrm{MPa})$. PCL even after foaming appears to be the reinforcing polymer while PBAT still acts as a matrix to transfer stress. Moreover, comparing the coaxial fibers with the foamed coaxial fibers, the results show that mechanical properties varied based on the location of porous polymer with regard to sheath versus core. For PCL(cPBAT) sample where

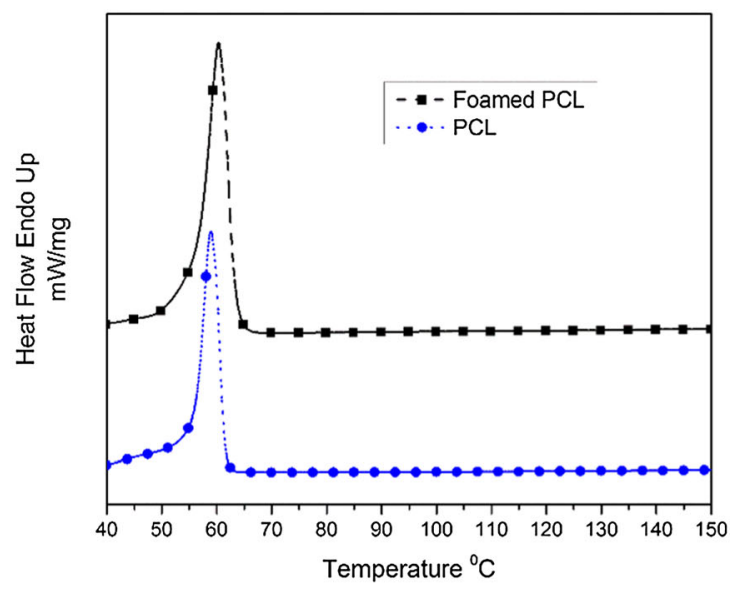

b

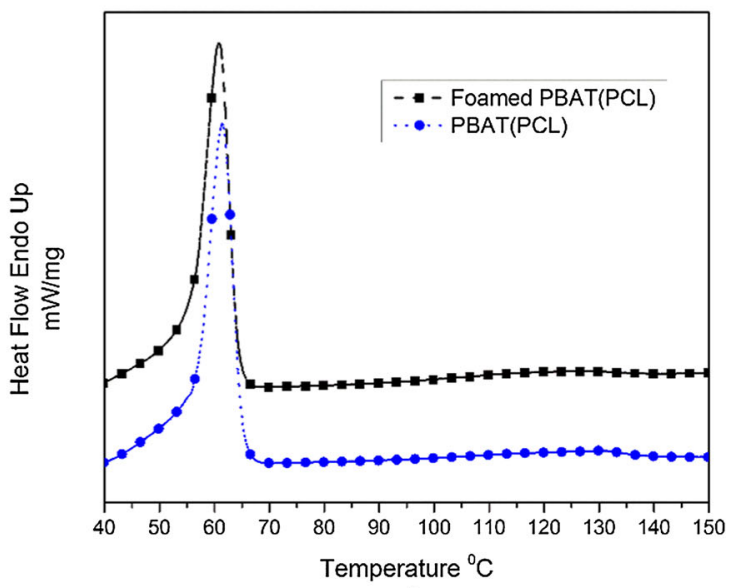

d

Fig. 5 Heating scan of a PBAT, b fPCL and PCL, $\mathbf{c}$ fPCL(cPBAT) and PCL(cPBAT), and $\mathbf{d}$ PBAT(cfPCL) and PBAT(cPCL) fibers 
Table 3 Thermal characteristic of the coaxial fiber mesh and foamed samples

\begin{tabular}{|c|c|c|c|c|c|c|c|c|}
\hline & \multicolumn{2}{|c|}{$\mathrm{T}_{\mathrm{m}}\left({ }^{\circ} \mathrm{C}\right)$} & \multicolumn{2}{|c|}{$\mathrm{T}_{\mathrm{c}}\left({ }^{\circ} \mathrm{C}\right)$} & \multicolumn{2}{|c|}{$\Delta \mathrm{H}_{\mathrm{m}}(\mathrm{J} / \mathrm{g})$} & \multicolumn{2}{|c|}{$\Delta \mathrm{H}_{\mathrm{c}}(\mathrm{J} / \mathrm{g})$} \\
\hline & PCL & PBAT & PCL & PBAT & PCL & PBAT & PCL & PBAT \\
\hline PBAT & - & 122 & - & 95 & - & 10.3 & - & 13.5 \\
\hline PCL & 59 & - & 38 & - & 65.2 & - & 67.2 & - \\
\hline fPCL & 60 & - & 36 & - & 53.1 & - & 47.3 & - \\
\hline PCL(cPBAT) & 58 & 117 & 33 & 87 & 72.0 & 0.45 & 46.8 & 0.39 \\
\hline fPCL(cPBAT) & 59 & 123 & 34 & 88 & 64.0 & 0.55 & 42.1 & 0.62 \\
\hline PBAT(cPCL) & 61 & 129 & 27 & 83 & 46.8 & 2.88 & 28.6 & 1.7 \\
\hline PBAT(cfPCL) & 61 & 121 & 31 & 83 & 44.2 & 1.91 & 36.4 & 2.1 \\
\hline
\end{tabular}

the $\mathrm{CO}_{2}$ miscible material is in the sheath of fiber, hence pores on the surface enhanced the stiffness of the material, from 53 to $71 \mathrm{MPa}$, i.e., an increase of $34 \%$ whereas the yield strength increase by $40 \%$. However, when the pores are present in the core of coaxial fiber, modulus of the drops from 61 to $33 \mathrm{MPa}$, which is a $46 \%$ reduction. There was no significant effect of on the tensile strength of the coaxial fibers due to foaming. This variation in the mechanical properties can be due to radially confined foaming of PBAT(cPCL) coaxial fiber as the core is surrounded by $\mathrm{CO}_{2}$ immiscible material.

The modulus of the coaxial fibers was also examined applying the micromechanics rule of mixture approach (Eq. 4).

$E=E_{c} V_{c}+E_{s} V_{s} \ldots \ldots \ldots$

where $\mathrm{E}, \mathrm{E}_{\mathrm{c}}$, and $\mathrm{E}_{\mathrm{s}}$ are modulus of composite; core and sheath V_c, V_s are volume fraction of core and sheath polymer.

The results (Table 4) show that the predicted values of modulus based on pristine polymer properties are substantially less than the actual modulus achieved by coaxially forming the polymers. For PCL(CPBAT), the measured modulus was $174 \%$ higher, whereas for PBAT(cPCL), it was $198 \%$ higher than the predicted values. This increase in the mechanical properties can be due to polymer chain entanglement at the interface of the polymers. After foaming, the location of the foamed polymers affected the mechanical advantage. For example, when the porous polymer was located as a sheath the measured modulus was $70.9 \mathrm{MPa}$ versus the predicted value of 18.34 indicating a benefit of $286 \%$ versus when it was in the core, the measured value was 33.2 versus a predicted value of 17.3.

Table 4 lists the mechanical properties of the electrospun pristine and coaxial fiber before and after foaming. Due to the non-uniform nature of porous samples, the difference in Young's modulus, tensile strength and yield strain of coaxial fabric and their foamed samples were analyzed using statistical methods. The results of $t$ test analysis with a significant level of 5\% showed that there is a significant difference between Young's modulus and yield stress of the coaxial composite fibers before and after foaming. However, there was no significant difference in tensile strength of the samples.
ANOVA test was also performed, which confirmed the mean value of modulus and yield stress is significantly different.

\subsubsection{Dynamic mechanical analysis}

Viscoelastic behavior of the coaxial fiber with different architecture were compared with the individual components using dynamic mechanical analysis at fixed frequency of $1 \mathrm{~Hz}$. Figure 8 shows storage modulus verses temperature plot for the PBAT, PCL, fPCL, and coresheath fibers of PCL(cPBAT), fPCL(cPBAT), PBAT(cPCL), and PBAT(cfPCL) fibers. The storage modulus (E') characterizes the in-phase response of the viscoelastic material, i.e., the elastic response of the material. It signifies the stiffness and the energy stored in the material when a load is applied. Modulus values are highest in the glassy region because of restricted chain mobility, a sharp drop in the storage modulus is observed in the glass transition region due to mobility of amorphous chains with the increase in vibrational and thermal energy, and finally we have a rubbery plateau due to strong interaction with the neighboring chains [40]. The storage modulus for all the coaxial fibers is clearly superior throughout the glassy, glass transition and rubbery region as compared to the pristine PCL, PBAT. The value in the glassy region are about $40 \mathrm{MPa}, 90 \mathrm{MPa}$, $600 \mathrm{MPa}$, and $1400 \mathrm{MPa}$ for pristine $\mathrm{PCL}$, pristine PBAT, coaxial PCL(cPBAT), and coaxial PBAT(cPCL). Porosity in the sheath of the fiber further increases the glassy modulus of the coaxial fibers by $13.5 \%$ in the glassy region. However, for pores in the core of the fibers cause a reduction in the stiffness of fibers by $50 \%$. The value of storage modulus in the rubbery region also followed the similar trend with values of $3.5 \mathrm{MPa}$ and $10 \mathrm{MPa}$ for Pristine PBAT and PCL, whereas for coaxial PCL (cPBAT) and coaxial PBAT (cPCL) the values are $100 \mathrm{MPa}$ and $250 \mathrm{MPa}$.

DMA results show a similar trend as observed from the tensile test, i.e., the foaming causes an increase in the elastic response of the PCL(cPBAT) fibers resulting in an 


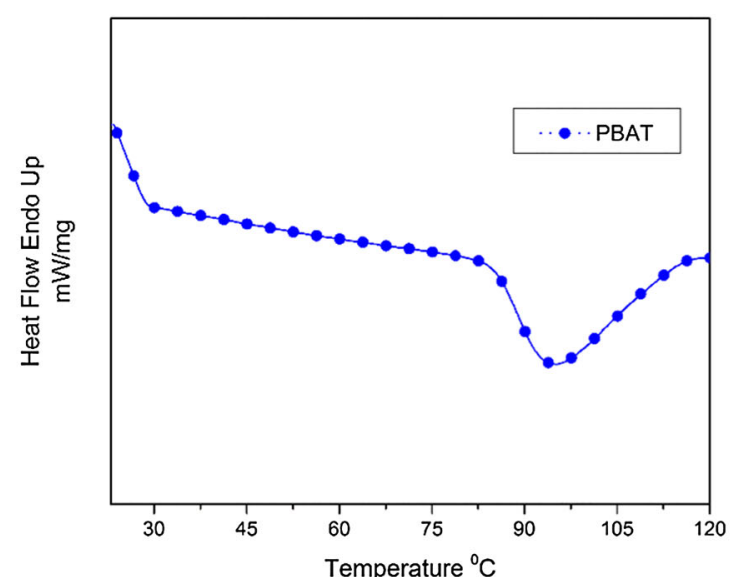

a

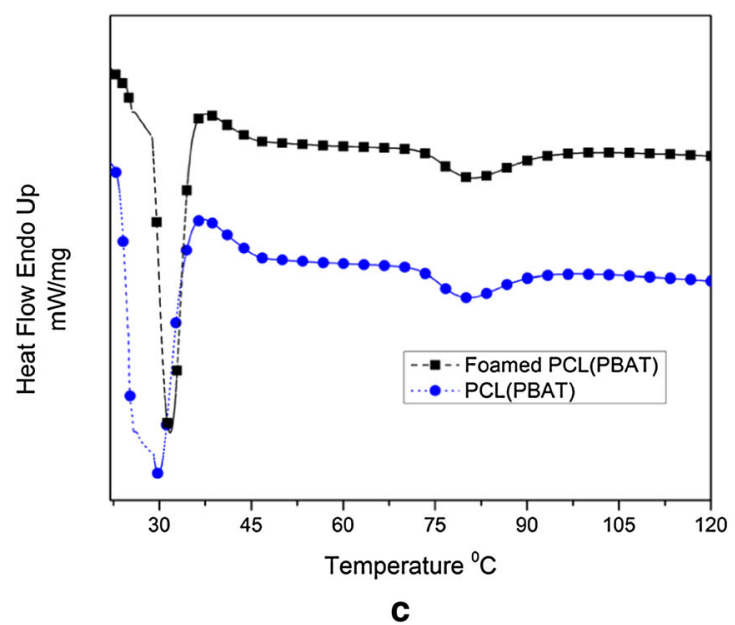

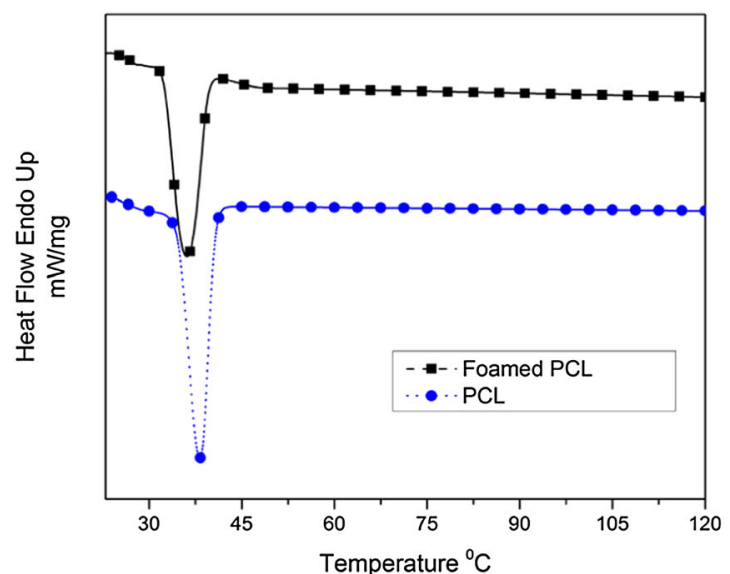

b

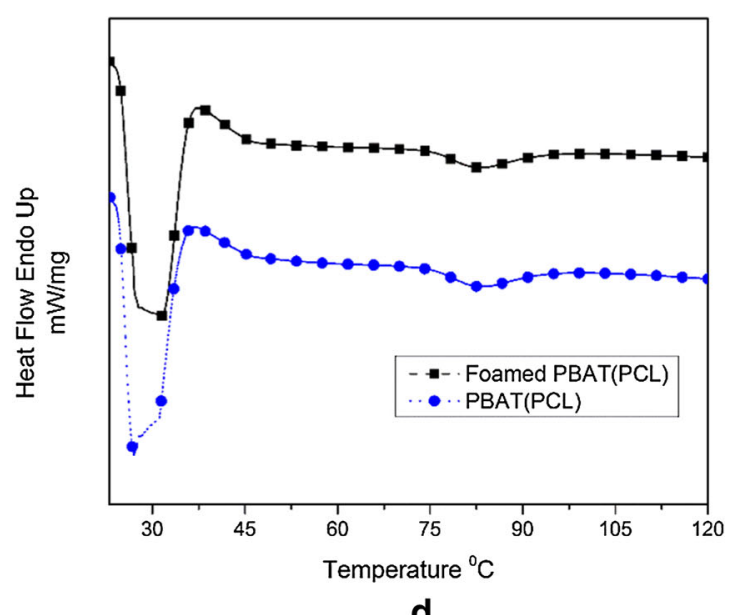

Fig. 6 Cooling scan of a PBAT fibers, $\mathbf{b}$ fPCL and PCL fibers, $\mathbf{c}$ fPCL(cPBAT) and PCL(cPBAT) fibers, and $\mathbf{d}$ PBAT(cfPCL) and PBAT(cPCL) fibers

increase in Young's modulus and storage modulus, while a decrease in Young's modulus and storage modulus for PBAT(cPCL) fibers. However, we observe a much higher value of storage modulus as compared to Young's modulus. The difference in the values is due to the distinct attribute of each technique. The tensile test gives quasistatic time independent response. The transient loading conditions and higher strain rates make it distinct to the DMA response, which is normally performed at much lower strain rate and gives dynamic time-dependent response for the loading. For materials with insignificant damping, Young's modulus is equivalent to storage modulus [40]. However, the difference in magnitude of both observed is due to the viscoelastic nature of the fibers having a high damping property.

Figure 9 shows loss modulus verses temperature plot for the PBAT, PCL, fPCL, and core-sheath fibers of PCL(cPBAT), fPCL(cPBAT), PBAT(cPCL), and PBAT(cfPCL) fibers. Loss modulus (E") characterizes the energy dissipation and viscous response of the material, where the maximum value of occurs within the glass transition region. The peak value for pristine PBAT and
PCL occurs at $-30{ }^{\circ} \mathrm{C}$ and $-50{ }^{\circ} \mathrm{C}$. For coaxial PCL(cPBAT) and PBAT(cPCL) two distinct peak are observed, one for each PBAT and PCL. The magnitude of loss modulus for coaxial fibers is clearly higher than the pristine polymers, showing higher damping property for the coaxial fabric. Interestingly, the magnitude of the loss modulus peak of sheath polymer for both PCL(cPBAT) and PBAT(cPCL) is greater than the peak of core polymer (Fig. 9). This can be due to the confinement of core polymer causing restriction in the mobility of core polymer chains due to strong interfacial interaction. Incorporation of porosity in the core [PBAT(cfPCL)] shows a reduction in the viscous response of the fabric. Moreover, the width of the loss modulus peak becomes narrow as both peak move closer to one another. This shift in the peak might be related to local physical interaction [41]. It is also interesting to note that PCL loss modulus peak magnitude after foaming is converted into a shoulder showing minor transition for porous PCL (Fig. 9 c). Loss modulus peak for fPCL(cPBAT) shows an interesting feature as the sheath of PCL transform to porous structure, the confined PBAT showed a higher 

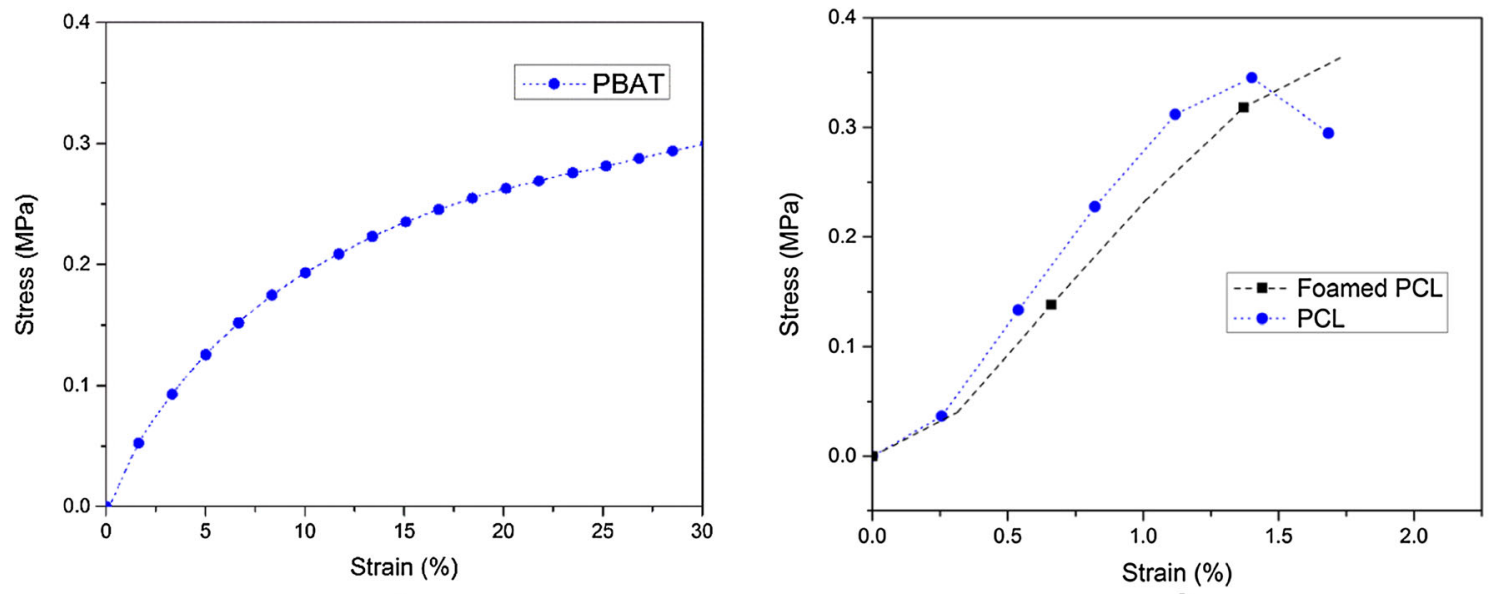

a

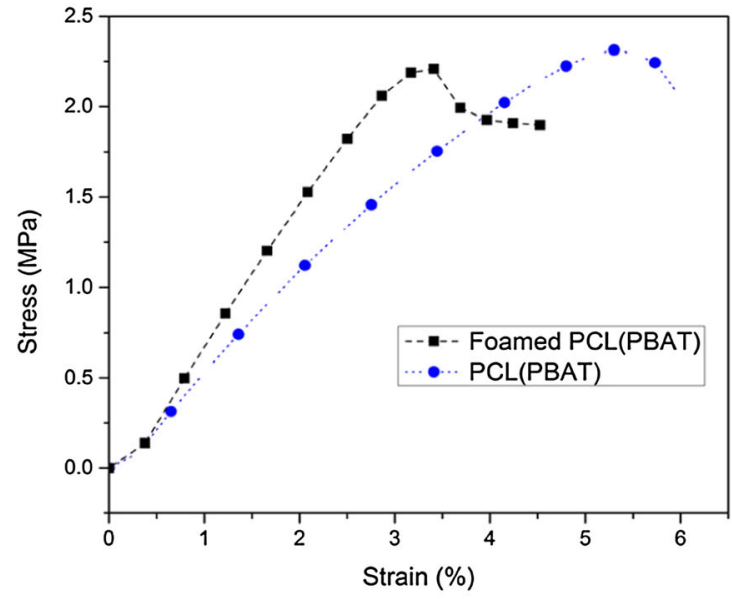

C

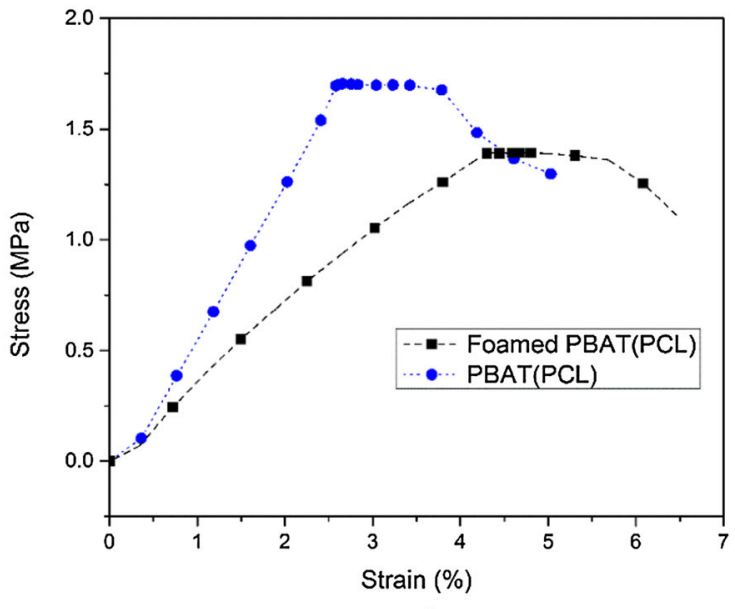

d

Fig. 7 Stress-strain curves of a PBAT fibers, $\mathbf{b}$ fPCL and PCL fibers, $\mathbf{c}$ PPCL(cPBAT) and PCL(cPBAT) fibers, and $\mathbf{d}$ foamed PBAT(cPCL) and PBAT(cPCL) fibers

peak indicating limited molecular mobility of polymer chain [42]. Regardless of location, the storage and loss moduli of the coaxial fibers were significantly higher than that of the single component fibers.

\section{Conclusions}

In this work, we have used the nature-inspired fiber design to form new synthetic fibers. We use physical foaming and preferential solubility of supercritical $\mathrm{CO}_{2}$ in PCL and insolubility in PBAT to foam electrospun fiber meshes. The effect of porosity on the mechanical properties of core-sheath fibers of PCL and PBAT were comprehensively analyzed using Quasi-static and dynamic loading techniques. The mechanical properties of core-sheath fibers were also compared with constituent material of PCL and PBAT. The major outcomes of this work provide a framework to utilize the new architecture:
1. Notable to our manufacturing approach is that the porosity was successfully introduced in the core as well as sheath while maintaining the structural integrity of the fiber. Cross-sectional image of coaxial fiber shows promising results indicating an optimal coaxial spinning; there was no physical detachment of the two polymer surface after $\mathrm{CO}_{2}$ exposure indicating a successful amalgamation of polymers at the boundary of core and sheath.

2. The coaxial architecture of both PCL(cPBAT) and PBAT(cPCL) fibers shows substantial enhancement in tensile strength, for PCL(cPBAT) strength increase by $650 \%$ and $468 \%$ compared to compared to pristine PCL and PBAT, whereas for PBAT(cPCL) the tensile strength increase by $450 \%$ and $315 \%$ compared to constituent PCL and PBAT respectively.

3. Introduction of porosity on the surface of coaxial fiber PPCL(cPBAT) further enhanced the stiffness of the material, from 53 to $71 \mathrm{MPa}$, i.e., an increase 
Table 4 Mechanical properties of the coaxial fiber mesh and foamed samples

\begin{tabular}{llllllll}
\hline & $\begin{array}{l}\text { Measured Young } \\
\text { modulus E (MPa) }\end{array}$ & $\begin{array}{l}\text { Predicted Young } \\
\text { modulus E }(\mathrm{MPa})\end{array}$ & $\begin{array}{l}\text { Tensile strength } \sigma \\
(\mathrm{MPa})\end{array}$ & $\begin{array}{l}\text { Yield strain } \\
\varepsilon_{\mathrm{y}}(\%)\end{array}$ & $\begin{array}{l}\text { Yield stress } \sigma_{\mathrm{y}} \\
(\mathrm{MPa})\end{array}$ & $\begin{array}{l}\text { Stress core } \\
(\mathrm{MPa})\end{array}$ & $\begin{array}{l}\text { Stress sheath } \\
(\mathrm{MPa})\end{array}$ \\
\hline PBAT & $1.85 \pm 0.94$ & & $0.41 \pm 0.11$ & $11.1 \pm 6.0$ & $0.19 \pm 0.03$ & - & - \\
$\mathrm{PCL}$ & $30.7 \pm 10.7$ & & $0.31 \pm 0.08$ & $1.21 \pm 0.47$ & $0.28 \pm 0.09$ & - & - \\
$\mathrm{fPCL}$ & $25.7 \pm 5.66$ & & $0.36 \pm 0.08$ & $1.36 \pm 0.10$ & $0.33 \pm 0.07$ & - \\
PCL(cPBAT) & $53.1 \pm 8.54$ & 19.38 & $2.33 \pm 0.34$ & $2.54 \pm 0.19$ & $1.35 \pm 0.21$ & $0.129 \pm 0.02$ & $2.15 \pm 0.32$ \\
$\mathrm{fPCL}(\mathrm{cPBAT})$ & $70.9 \pm 10.3$ & 18.34 & $2.23 \pm 0.24$ & $2.63 \pm 0.35$ & $1.88 \pm 0.21$ & $0.19 \pm 0.02$ & $2.64 \pm 0.29$ \\
PBAT(cPCL) & $61.6 \pm 6.03$ & 20.73 & $1.70 \pm 0.11$ & $2.25 \pm 0.46$ & $1.52 \pm 0.41$ & $2.25 \pm 0.61$ & $0.135 \pm 0.03$ \\
PBAT(cfPCL) & $33.2 \pm 4.38$ & 17.89 & $1.62 \pm 0.57$ & $2.4 \pm 0.34$ & $1.28 \pm 0.67$ & $1.88 \pm 0.98$ & $0.135 \pm 0.07$ \\
\hline
\end{tabular}

of $34 \%$ whereas the yield strength also increases by $40 \%$.

4. Modulus examined through rule of mixture approach shows significant mechanical advantage achieved by blending fibers using coaxial approach, for PCL(cPBAT) the measured modulus was $174 \%$ higher, PBAT(cPCL), it was $198 \%$, PBAT(cfPCL), it was $90 \%$ higher, whereas for PPCL(cPBAT), it was $287 \%$ higher than the predicted values, indicating strong interfacial strength between the two.

5. The storage and loss modulus for coaxial fibers are superior throughout the glassy, glass transition and rubbery region as compared to the pristine PCL, PBAT, showing enhancement in both the elastic and viscous response of the material.
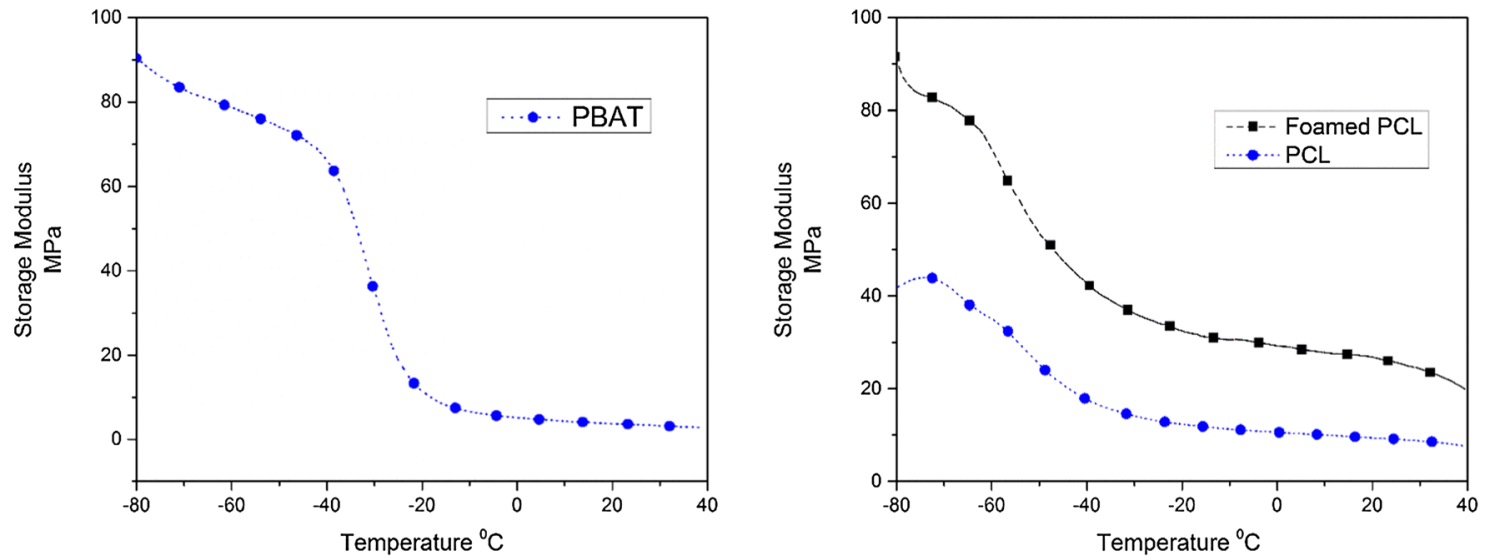

a
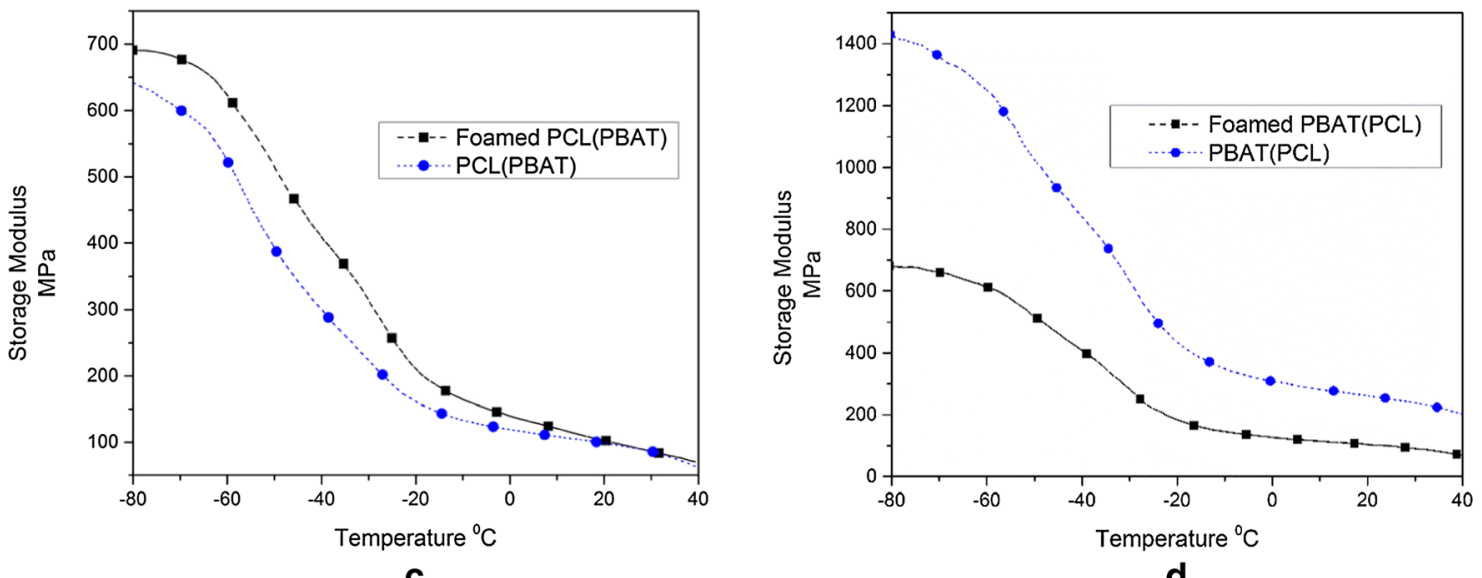

Fig. 8 Storage modulus vs temperature of a PBAT fibers, $\mathbf{b}$ f PCL and PCL fibers, $\mathbf{c}$ fPCL(cPBAT) and PCL(cPBAT) fibers, and $\mathbf{d}$ PBAT(cfPCL) and PBAT(CPCL) fibers 

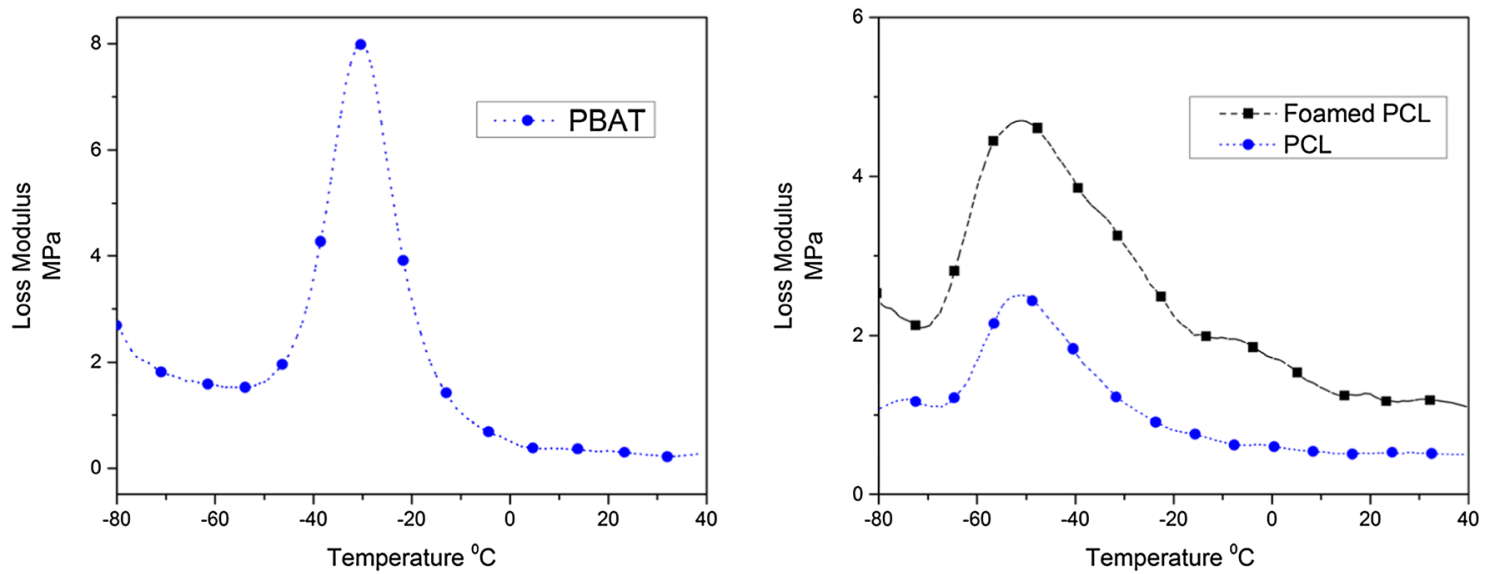

a
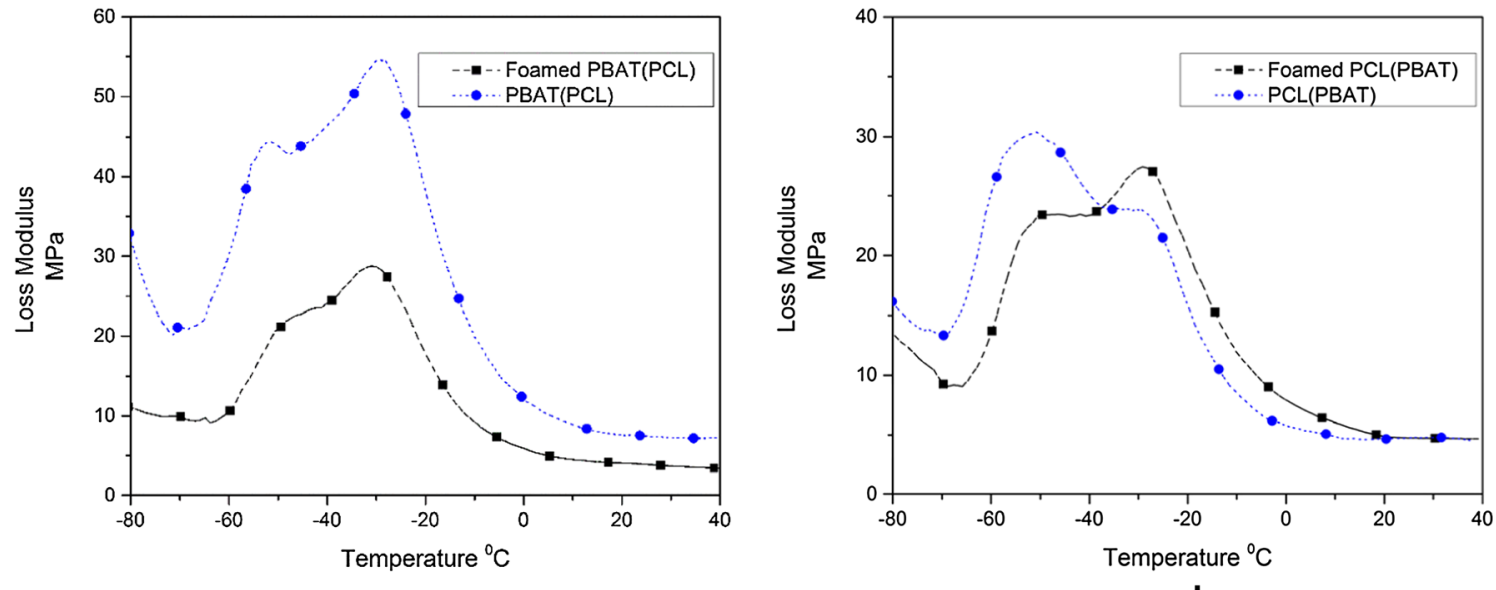

C

d

Fig. 9 Loss modulus vs temperature of a PBAT fibers, $\mathbf{b}$ fPCL and PCL fibers, $\mathbf{c}$ fPCL(cPBAT) and PCL(cPBAT) fibers, and $\mathbf{d}$ PBAT(cfPCL) and PBAT(cPCL) fibers

6. A shift in glass transition temperature indicated by the tan $\delta$ peak for coaxial fibers to lower temperature as compared to pristine PCL and PBAT, indicating coupling increases the segmental mobility of the amorphous PCL and PBAT chains.

The results show that utilizing variances in $\mathrm{CO}_{2}$ miscibility of two polymers, we can successfully manipulate the architecture of the cross section of the electrospun fiber and can tailor the mechanical properties to the required application. This new architecture presents a new design platform for functional biomaterials. The outcomes have a transformational impact on the design of sutures and tissue scaffolds particularly where drug delivery and other transport phenomena are needed. Surface porosity induced by a non-volatile organic compound such as carbon dioxide has a potential to reduce the inflammatory response in the body. Further porosity offers a high surface area for drug delivery per unit volume. This paper explored the impact of porosity with the results indicating that surface porosity induced by a nonvolatile organic compound such as $\mathrm{CO}_{2}$ creates a unique higher mechanically robust fiber architecture. Applications with a need for mechanical and transport properties such as biomedical applications can benefit from it.

Acknowledgements Financial support was provided by National Science Foundation NSF-CMMI 1728096

Open Access This article is distributed under the terms of the Creative Commons Attribution 4.0 International License (http:// creativecommons.org/licenses/by/4.0/), which permits unrestricted use, distribution, and reproduction in any medium, provided you give appropriate credit to the original author(s) and the source, provide a link to the Creative Commons license, and indicate if changes were made.

\section{References}

1. B.G. Ayre, K. Stevens, K.D. Chapman, C.L. Webber, K.L. Dagnon, N.A. D'Souza, Viscoelastic properties of kenaf bast fiber in relation to stem age. Text. Res. J. 79(11), 973-980 (2009). https://doi.org/ 10.1177/0040517508100185

2. D. Ramesh, B.G. Ayre, C.L. Webber, N.A. D'Souza, Dynamic mechanical analysis, surface chemistry and morphology of alkali 
and enzymatic retted kenaf fibers. Text. Res. J 85, 2059-2070 (2015)

3. D'Souza, NA, Allen, MS, Stevens, K. Ayre, B., Visi, DK, Vidhate, S. Ghamarian, I, and. Webber, CL III, "Biocomposites: the natural fiber contribution from bast and woody plants". In: C.L. Webber III and A. Liu (Eds.). Plant fibers as renewable feedstocks for biofuel and bio-based products. CCG International Inc (2011)

4. J. Guan, J. Li, Y. Li, Electrospun nanofibers with both surface nanopores and internal interpenetrated nanochannels for oil absorption. RSC Adv. 6(40), 33781-33788 (2016). https://doi.org/10. 1039/C6RA00678G

5. H. Xu, Q. Li, Deformation mechanisms and mechanical properties of porous magnesium/carbon nanofiber composites with different porosities. J. Mater. Sci. 53(20), 14375-14385 (2018). https://doi. org/10.1007/s10853-018-2649-x

6. J. Yin, D. Zhang, Y. Xiang, P. Wei, Z. Yang, Z. Wang, J. Fu, The influence of cross-sectional morphology on the compressive resistance of polymeric nerve conduits. Polymer 148, 93-100 (2018)

7. C.J. Cooper, A.K. Mohanty, M. Misra, Electrospinning process and structure relationship of biobased poly(butylene succinate) for nanoporous fibers. ACS Omega 3(5), 5547-5557 (2018). https:// doi.org/10.1021/acsomega.8b00332

8. S. Huan, G. Liu, W. Cheng, G. Han, L. Bai, Electrospun poly(lactic acid)-based fibrous nanocomposite reinforced by cellulose nanocrystals: impact of fiber uniaxial alignment on microstructure and mechanical properties. Biomacromolecules 19(3), 1037-1046 (2018). https://doi.org/10.1021/acs.biomac.8b00023

9. D.H. Reneker, A.L. Yarin, H. Fong, S. Koombhongse, Bending instability of electrically charged liquid jets of polymer solutions in electrospinning. J. Appl. Phys. 87(9), 4531-4547 (2000). https:// doi.org/10.1063/1.373532

10. Z. Sun, E. Zussman, A.L. Yarin, J.H. Wendorff, A. Greiner, Compound core-shell polymer nanofibers by Co-electrospinning. Adv. Mater. 15(22), 1929-1932 (2003). https://doi.org/10.1002/ adma. 200305136

11. M.F. Elahi, W. Lu, Core-shell fibers for biomedical applications-a review. J. Bioeng. Biomed. Sci. 3(1) (2013). https://doi.org/10. 4172/2155-9538.1000121

12. S. Megelski, J.S. Stephens, D.B. Chase, J.F. Rabolt, Micro- and nanostructured surface morphology on electrospun polymer fibers. Macromolecules 35(22), 8456-8466 (2002). https://doi.org/10. $1021 / \mathrm{ma} 020444 \mathrm{a}$

13. R.M. Nezarati, M.B. Eifert, E. Cosgriff-Hernandez, Effects of humidity and solution viscosity on electrospun fiber morphology. Tissue Eng. Part C: Methods 19(10), 81-819 (2013). https://doi. org/10.1089/ten.tec.2012.0671

14. J.T. McCann, M. Marquez, Y. Xia, Highly porous fibers by electrospinning into a cryogenic liquid. J. Am. Chem. Soc. 128(5), 1436-1437 (2006). https://doi.org/10.1021/ja056810y

15. K.A.G. Katsogiannis, G.T. Vladisavljević, S. Georgiadou, Porous electrospun polycaprolactone (PCL) fibres by phase separation. Eur. Polym. J. 69, 284-295 (2015). https://doi.org/10.1016/j. eurpolymj.2015.01.028

16. P. Chen, S. Tung, One-step electrospinning to produce nonsolventinduced macroporous fibers with ultrahigh oil adsorption capability. Macromolecules 50(6), 2528-2534 (2017). https://doi.org/10.1021/ acs.macromol.6b02696

17. D. Zhang, N. Zhang, F. Ma, X.D. Qi, J.H. Yang, T. Huang, Y. Wang, One-step fabrication of functionalized poly(l-lactide) porous fibers by electrospinning and the adsorption/separation abilities. J. Hazard. Mater. 360, 150-162 (2018). https://doi.org/10.1016/j. jhazmat.2018.07.090

18. K. Nayani, H. Katepalli, C.S. Sharma, A. Sharma, S. Patil, R. Venkataraghavan, Electrospinning combined with nonsolventinduced phase separation to fabricate highly porous and hollow submicrometer polymer fibers. Ind. Eng. Chem. Res. 51(4), 1761-1766 (2012). https://doi.org/10.1021/ie2009229

19. A. Gupta, C.D. Saquing, M. Afshari, A.E. Tonelli, S.A. Khan, R. Kotek, Porous nylon-6 fibers via a novel salt-induced electrospinning method. Macromolecules 42(3), 709-715 (2009). https://doi.org/10.1021/ma801918c

20. D.J. Mooney, D.F. Baldwin, N.P. Suh, J.P. Vacanti, R. Langer, Novel approach to fabricate porous sponges of poly(d,1-lactic-coglycolic acid) without the use of organic solvents. Biomaterials 17(14), 1417-1422 (1996). https://doi.org/10.1016/0142-9612(96) $87284-X$

21. A.R.C. Duarte, R.M. Duarte, J. Correia-Pinto, et al., Subcritical carbon dioxide foaming of polycaprolactone for bone tissue regeneration. J. Supercrit. Fluids 140,1-10 (2018). https://doi.org/10. 1016/j.supflu.2018.05.019

22. M.M. Rahman, J. Lillepärg, S. Neumann, S. Shishatskiy, V. Abetz, A thermodynamic study of $\mathrm{CO}_{2}$ sorption and thermal transition of PolyActive ${ }^{\mathrm{TM}}$ under elevated pressure. Polymer 93, 132-141 (2016). https://doi.org/10.1016/j.polymer.2016.04.024

23. H.W. Seo, Y.J. Kim, S. Kim, J. Park, K. Choi, I.K. Park, T. Kim, J. Suhr, K.J. Kim, J.D. Nam, Nanoplatelet reinforcement of cavity cell walls in polymer foams using carbon dioxide supercritical fluid. J. Appl. Polym. Sci. 135(33), 46615 (2018). https://doi.org/10.1002/ app.46615

24. K.J. France, F. Xu, T. Hoare, Structured macroporous hydrogels: progress, challenges, and opportunities. Adv. Healthcare Mater. 7(1), n/a (2018). https://doi.org/10.1002/adhm.201700927

25. D.L. Tomasko, H. Li, D. Liu, X. Han, M.J. Wingert, L.J. Lee, K.W. Koelling, A review of $\mathrm{CO}_{2}$ applications in the processing of polymers. Ind. Eng. Chem. Res. 42(25), 6431-6456 (2003). https://doi. org/10.1021/ie030199z

26. J. Liu, Z. Shen, S. Lee, et al., Electrospinning in compressed carbon dioxide: Hollow or open-cell fiber formation with a single nozzle configuration. J. Supercrit. Fluids 53(1), 142-150 (2010). https:// doi.org/10.1016/j.supflu.2010.02.016

27. Wahyudiono, S. Machmudah, H. Kanda, et al., Formation of PVP hollow fibers by electrospinning in one-step process at sub and supercritical $\mathrm{CO}_{2}$. Chem. Eng. Process. Process Intensif. 77, 1-6 (2014). https://doi.org/10.1016/j.cep.2013.12.007

28. K. Okamoto, S. Machmudah, H. Kanda, et al., Generation of multihollow structured poly(methyl methacrylate) fibers by electrospinning under pressurized $\mathrm{CO}_{2}$. Polym. Eng. Sci. 56(7), 752-759 (2016). https://doi.org/10.1002/pen.24302

29. I. Muhammad, M. Nunzio, S. Mahnaz, Electrospun onedimensional nanostructures: a new horizon for gas sensing materials. Beilstein Journal of Nanotechnology 9, 2128-2170 (2018). https://doi.org/10.3762/bjnano.9.202

30. J. Ge, D. Zong, Q. Jin, et al., Biomimetic and superwettable nanofibrous skins for highly efficient separation of oil-in-water emulsions. Adv. Funct Mater. 28(10), n/a (2018). https://doi.org/ 10.1002/adfm.201705051

31. L. Dong, C. Xu, Y. Li, Z.H. Huang, F. Kang, Q.H. Yang, X. Zhao, Flexible electrodes and supercapacitors for wearable energy storage: a review by category. J. Mater. Chem. A, Mater. Energy Sustain. 4(13), 4659-4685 (2016). https://doi.org/10.1039/ c5ta10582j

32. A. Khalf, S.V. Madihally, Recent advances in multiaxial electrospinning for drug delivery. Eur. J. Pharm. Biopharm. 112, 1-17 (2017). https://doi.org/10.1016/j.ejpb.2016.11.010

33. X. Hu, S. Liu, G. Zhou, Y. Huang, Z. Xie, X. Jing, Electrospinning of polymeric nanofibers for drug delivery applications. J. Control. Release 185, 12-21 (2014). https://doi.org/10.1016/j.jconrel.2014. 04.018

34. S.A. Arvidson, K.C. Wong, R.E. Gorga, S.A. Khan, Structure, molecular orientation, and resultant mechanical properties in core/ 
sheath poly(lactic acid)/polypropylene composites. Polymer 53(3), 791-800 (2012)

35. Y. Zhang, Z. Huang, X. Xu, et al., Preparation of core-shell structured PCL-r-gelatin Bi-component nanofibers by coaxial electrospinning. Chem. Mater. 16(18), 3406-3409 (2004). https:// doi.org/10.1021/cm049580f

36. T.K. Dash, V.B. Konkimalla, Poly-€-caprolactone based formulations for drug delivery and tissue engineering: A review. J. Control. Release 158(1), 15-33 (2012). https://doi.org/10.1016/j.jconrel. 2011.09.064

37. J. Pu, K. Komvopoulos, Mechanical properties of electrospun bilayer fibrous membranes as potential scaffolds for tissue engineering. Acta Biomater. 10(6), 2718-2726 (2014). https://doi.org/10. 1016/j.actbio.2013.12.060

38. O. Ero-Phillips, M. Jenkins, A. Stamboulis, Tailoring crystallinity of electrospun plla fibres by control of electrospinning parameters.
Polymers 4(3), 1331-1348 (2012). https://doi.org/10.3390/ polym 4031331

39. V. Kumar, N.P. Suh, A process for making microcellular thermoplastic parts. Polym. Eng. Sci. 30(20), 1323-1329 (1990). https:// doi.org/10.1002/pen.760302010

40. W.J. MacKnight, S. MacKnight, T. Montgomery, et al., Introduction to polymer viscoelasticity, 4th edition edn. (Wiley, US, 2018)

41. H.F. Alharbi, M. Luqman, H. Fouad, K.A. Khalil, N.H. Alharthi, Viscoelastic behavior of core-shell structured nanofibers of PLA and PVA produced by coaxial electrospinning. Polym. Test. 67, 136-143 (2018). https://doi.org/10.1016/j.polymertesting.2018.02. 026

42. N.B. Erdal, M. Hakkarainen, Construction of bioactive and reinforced bioresorbable nanocomposites by reduced Nano-graphene oxide carbon dots. Biomacromolecules 19(3), 1074-1081 (2018). https://doi.org/10.1021/acs.biomac.8b00207 